\title{
PZT-NZF/CF ferrite flexible thick films: Structural, dielectric, ferroelectric, and magnetic characterization
}

\author{
J. D. BOBIĆ ${ }^{a, *}$, G. Ferreira TEIXEIRA ${ }^{b}$, R. GRIGALAITIS ${ }^{c}$, S. GYERGYEK ${ }^{d}$, \\ M. M. Vijatović PETROVIĆ ${ }^{a}$, M. Ap. ZAGHETE ${ }^{e}$, B. D. STOJANOVIC ${ }^{a}$ \\ ${ }^{a}$ Institute for Multidisciplinary Research, Belgrade University, Kneza Viseslava 1, Belgrade, Serbia \\ ${ }^{b}$ Universidade Federal de Goiás - UFG, Instituto de Química, Av Esperança s/n, Goiânia, GO, Brazil \\ ${ }^{c}$ Faculty of Physics, Vilnius University, Sauletekio al. 9, Vilnius, Lithuania \\ ${ }^{d}$ Institute Jozef Stefan, Jamova cesta 39, Ljubljana, Slovenia \\ ${ }^{e}$ Instituto de Quimica-UNESP, Araraquara, S.P., Brazil
}

Received: December 6, 2018; Revised: April 16, 2019; Accepted: May 3, 2019

(C) The Author(s) 2019.

\begin{abstract}
The preparation and properties of thick flexible three-phase composite films based on lead zirconium titanate (PZT) and various ferrites (nickel zinc ferrite (NZF) and cobalt ferrite (CF)) were reported in this study. Properties of three-phase composite films were compared with pure polyvinylidene fluoride (PVDF) and PZT-PVDF films. X-ray diffraction data indicated the formation of well crystallized structure of PZT and NZF/CF phases, without the presence of undesirable phases. Scanning electron micrographs showed that the ceramic particles were dispersed homogeneously in the PVDF matrix and atomic force microscopy confirmed that the size of the particles is around $30 \mathrm{~nm}$. Non-saturated hysteresis loops were evident in all samples due to the presence of highly conductive ferrite phases. Under magnetic field of $10 \mathrm{kOe}$, composite films exhibited a typical ferromagnetic response. Dielectric properties were investigated in the temperature range from -128 to $250{ }^{\circ} \mathrm{C}$ and frequency range of $400 \mathrm{~Hz}-1 \mathrm{MHz}$. The results showed that the value of dielectric constant of the PVDF/PZT/ferrite composites increased about $25 \%$ above the one obtained for pure PVDF.
\end{abstract}

Keywords: flexible thick films; three-phase composites; ferroelectricity; magnetic materials

\section{Introduction}

A considerable attention has recently been focused on the development of technology for the growth of thick or thin films due to miniaturization requirements of electronic devices [1-4]. Besides extreme efforts to improve the performance of electronic devices that are

* Corresponding author.

E-mail: jelenabobic@yahoo.com based on hard and brittle substrates, a new challenge in electronics is the ability of the material to survive the mechanical deformation. Flexible electronics, which can be bent, rolled, and stretched into arbitrary shapes, would significantly expand the application of modern electronic devices in the areas of computation, communications, displays, sensing, energy harvesting, and storage devices [5-7]. The most common ways for the preparation of flexible films are gravity casting [8-11] and hot pressing method [12-14]. The simplified 
way to obtain composite thick films with different filler contents is a gravitational casting method. Pascariu et al. [10] employed this method in order to obtain flat composites with compositional gradient along the thickness direction and in-plane homogeneous composition. They found that compositional gradients can be controlled to some extent by changing the filler properties, the matrix density, and the casting parameters. To date, less frequently used method for obtaining the flexible films has been hot pressing where the mixture of polymer matrix and active component (filler) is pressed at around $200{ }^{\circ} \mathrm{C}$ after which the thick sheets are obtained. Literature data have shown that this approach is very effective in manufacturing 2-2 composite structures [15].

Further, ferroelectric polymers possess excellent flexibility and deformation, but their electrical activity is characterized by a field-independent low permittivity $(\varepsilon$ less than 10) $[9,16]$. As such, they could not be used as active functional materials in microelectronic applications. To circumvent these problems, flexible composite materials consisted of ferroelectric/ ferromagnetic ceramic filler and polymer may be an alternative material which combines the two properties of ceramic and mechanical properties of the polymer. As polyvinylidene fluoride (PVDF) has many interesting properties and advantages over other polymers, it has been selected to fabricate inorganic-organic nanocomposites with expectation to provide good dielectric and required properties as compared to traditional multilayer ceramics [14]. PVDF is a semi-crystalline polymer that can have ferroelectric order depending on the processing method. PVDF can be obtained in five different forms $\alpha, \beta, \gamma, \delta$, and $\varepsilon$, out of which $\alpha, \beta$, and $\gamma$ are most common phases [17,18]. $\alpha$-phase PVDF can be obtained from the melt or during polymerization and it is the unique among the most common phases that does not exhibit ferroelectric behavior [18]. The conversion of $\alpha$-phase into $\beta$-phase occurs at temperatures below $100{ }^{\circ} \mathrm{C}$ by stretching. Other way to achieve $\beta$-phase is promote the crystallization of polymer from its solution with dimethylformamide (DMF) or dimethylacetamide (DMA) at temperatures below $70{ }^{\circ} \mathrm{C}$ [19]. In spite that $\gamma$-phase is also electroactive, the $\beta$-phase is more used due to its properties of the ferroelectricity, pyroelectricity, and piezoelectricity $[17,20]$.

In this paper, the examination and characterization of the three-phase ceramic-polymer composites (PVDFPZT-ferrite) based on PZT as a ferroelectric phase with different ferrite phases as magnetic phase, as well as PZT-PVDF and pure PVDF films were performed. The main challenges of this study were to obtain flexible composite films and to combine the advantages of the different phases in order to modify the properties of pure PVDF. In that way these materials could be used for high electrostatic energy storage and for non-linear dielectric functional devices.

\section{Experimental procedure and methods}

Three-phase composite thick, flexible films $\left((x) \mathrm{PbZr}_{0.52}\right.$ $\mathrm{Ti}_{0.48} \mathrm{O}_{3}+(1-x) \mathrm{CoFe}_{2} \mathrm{O}_{4}$ and $(x) \mathrm{PbZr}_{0.52} \mathrm{Ti}_{0.48} \mathrm{O}_{3}+(1-x)$ $\mathrm{Ni}_{0.7} \mathrm{Zn}_{0.3} \mathrm{Fe}_{2} \mathrm{O}_{4}(x=0.8$ and 0.9$\left.)\right)$ as well as PZT-PVDF and PVDF films were prepared by hot pressing method. Firstly, the individual phases of $\mathrm{Ni}_{0.7} \mathrm{Zn}_{0.3} \mathrm{Fe}_{2} \mathrm{O}_{4}(\mathrm{NZF})$, $\mathrm{CoFe}_{2} \mathrm{O}_{4}(\mathrm{CF})$, and $\mathrm{PbZr}_{0.52} \mathrm{Ti}_{0.48} \mathrm{O}_{3}(\mathrm{PZT})$ were prepared by the autocombustion methods. Detailed powder preparation method was reported in Ref. [21]. Appropriate metal nitrates and citric acid solution were mixed by dissolving in a minimum amount of deionized water. The ammonia solution $\left(\mathrm{NH}_{4} \mathrm{OH}\right)$ was introduced into the solution to adjust the $\mathrm{pH}$ value to 7 . After that the solution was stirred and heated at the temperature of about $90{ }^{\circ} \mathrm{C}$ until it is converted into a xerogel, which was further heated in a heating calotte at $200{ }^{\circ} \mathrm{C}$ when self-propagation reaction was achieved. After the thermal treatment of NZF and CF precursor powders at $1000{ }^{\circ} \mathrm{C}$ for $1 \mathrm{~h}$ pure NZF and CF powders were obtained. The same procedure was used for obtaining PZT powder. Starting reagents were AR grade of the lead nitrate $\left(\mathrm{Pb}\left(\mathrm{NO}_{3}\right)_{2}\right)$, zirconium (IV) oxynitrate hydrate $\left(\mathrm{ZrO}\left(\mathrm{NO}_{3}\right)_{2} \cdot \mathrm{H}_{2} \mathrm{O}\right)$, titanium isopropoxide $\left(\mathrm{Ti}\left(\mathrm{OCH}\left(\mathrm{CH}_{3}\right)_{2}\right)_{4}\right)$, citric acid $\left(\mathrm{C}_{6} \mathrm{H}_{8} \mathrm{O}_{7} \cdot \mathrm{H}_{2} \mathrm{O}\right)$, and ammonium hydroxide $\left(\mathrm{NH}_{4} \mathrm{OH}\right)$. After the selfpropagation reaction and calcination of the $\mathrm{PZT}$ precursor powder at $800{ }^{\circ} \mathrm{C}$ for $2 \mathrm{~h}$, pure PZT powder was obtained. In order to get homogenous fine powder of desired composite compounds, mixing and homogenizing of PZT and NZF/CF powders were performed in a planetary ball mill for $24 \mathrm{~h}$ in the iso-propyl alcohol as a milling medium.

Flexible composites were prepared by mixing ceramic powders (PZT and PZT-NZF/CF) with PVDF (Alfa Aeser) in an agate mortar. As the packing of a ceramic powder into a polymer is limited, usually the content of the filler cannot exceed the volume fraction of $40 \mathrm{vol} \%$ [21]. The volume ratio between ceramic 
filler and polymer matrix in this study was $30 \mathrm{vol} \%$ to $70 \mathrm{vol} \%$ in the polymer composite. This volume ratio was chosen to reconcile requirements for characteristics on one side and flexibility of the films on the other. In order to prepare thick flexible films, the powder mixtures were placed between sheets of Kapton and hot pressed at $190{ }^{\circ} \mathrm{C}$ for $5 \mathrm{~min}$ with a pressure of $5 \mathrm{MPa}$. In the present study we have used $\alpha$-phase PVDF to give us a flexible material and to ensure that the ferroelectric behavior of the final sample is from ceramic component without interference of other material. After hot pressing, the composite flexible films (PVDF-PZT-ferrite, PVDF-PZT, and pure PVDF) with desired shapes (shown in Fig. 1(a)) were used for further characterization. It was found that the composite film showed good flexibility at high loading levels that could be explained by good compatibility between functionalized filler particles and the PVDF matrix. The cross section of the film was presented in Fig. 1(b) showing the thickness of around $50 \mu \mathrm{m}$.

XRD patterns of ceramic composites were recorded using X-ray diffraction technique (Model RIGAKU ${ }^{\circledR}$ RINT 2000 diffractometer, with Co $\mathrm{K} \alpha$ radiation, $0.5\left(^{\circ}\right) / \mathrm{min}$ ). Scanning electron microscope (Model TESCAN SM-300) was used for microstructural characterization of the films. The analysis was performed on the free surface and cross section of the films.
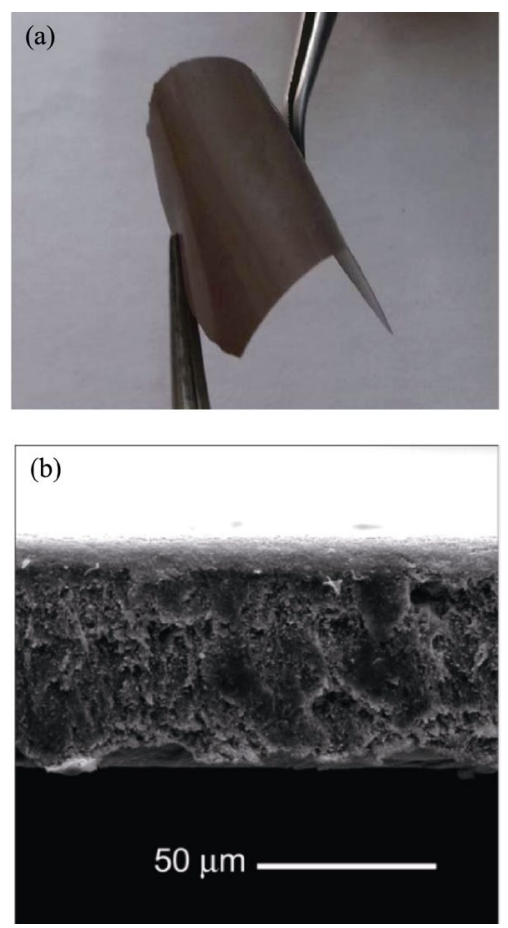

Fig. 1 Photographs showing (a) the final look of flexible composite film and (b) crosssection of the film.
Atomic force microscope (NT-MDT Ntegra SPM) was also used to provide information about morphology and surface roughness of the composite films. Dielectric permittivity measurements were carried out using an LCR meter (model 4284A, Hewllet-Packard) in the temperature range from -128 to $250{ }^{\circ} \mathrm{C}$ and frequency range from $100 \mathrm{~Hz}$ to $1 \mathrm{MHz}$. Samples were prepared for electrical measurements by sputtering gold electrodes on both sides of the flexible composite films. Ferroelectric measurements were carried out on Precision Multiferroic Test System with High Voltage Interface (Radiant Technologies, Inc.), and measurement conditions were $330 \mathrm{kV} / \mathrm{cm}$ at $1 \mathrm{~Hz}$. The magnetic moments were measured using a vibrating-sample magnetometer (VSM Lake Shore 7307) at room temperature.

\section{Results and discussion}

Figure 2 shows the XRD patterns of composite ceramicpolymer films consisting of perovskite structure of PZT and cubic spinel structure of CF and NZF. The diffraction peaks are in agreement with standard JCPDS Card Nos. 10-0325 and 22-1086, respectively. There is no evident existence of any secondary phases or formation of intermediate phase during synthesis of composite films. In the comparison with X-ray analysis of composite ceramics (previously published in Ref. [22]) in which diffraction peaks of all phases were sharp, XRD patterns of PVDF-PZT-ferrite samples showed the existence of broader peaks as a consequence of the presence of amorphous PVDF phase in the film.

The composite powder morphology of PZT-NZF (80-20) was presented in Fig. 3(a) and it is evident that this powder is very agglomerated with the largest dimensions of agglomerates around $1 \mu \mathrm{m}$. SEM was

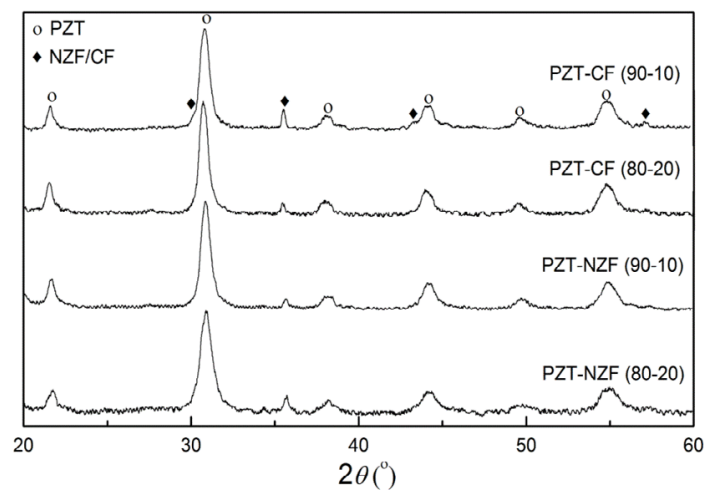

Fig. 2 XRD diffractograms of all investigated composite films. 

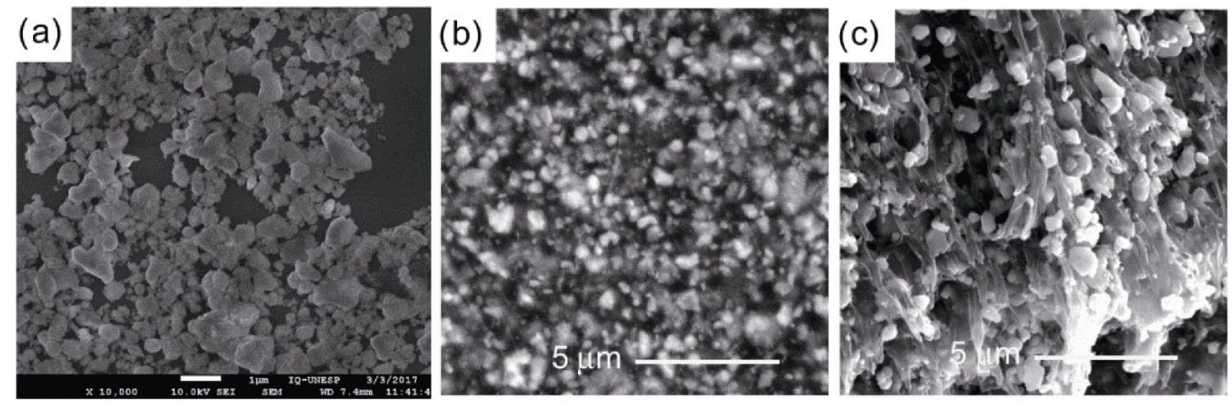

Fig. 3 SEM micrographs of (a) PZT-ferrite powder mixture, (b) free surface of PVDF-PZT-ferrite composite film, and (c) cross section of the film.

also employed to investigate the PZT and ferrite particle dispersion by imaging the free surface and transversely fractured films (Figs. 3(b) and 3(c)). Micrographs clearly display the regular shaped particles incorporated into the polymer matrix having clear boundaries between. In the case of the composites with different amount and kind of ferrite phase, a significant difference in the morphology of both phases was not observed. Atomic force microscopy was engaged in further surface analysis since it allowed the visualization of micro surfaces which were inaccessible by SEM. Figures 4(a) and 4(b) show the 2D and 3D images of PVDF-PZT-ferrite composite films, respectively. The roughness of the film is $\sim 15 \mathrm{~nm}$ which indicates the present rough surfaces covered more or less with granular formations with an agglomeration tendency. According to AFM the size of the particles is around $30 \mathrm{~nm}$.

It is important to point out that in all these samples, which are consisted of functional material in the polymer matrix, the effective distance between the electrodes can vary, which can complicate the interpretation of the experimental data obtained by both electric and ferroelectric characterizations. The polarization versus electric field $(P-E)$ hysteresis loops were recorded at room temperature in order to study the ferroelectric behavior of all composite films.

Due to the high conductivity of NZF/CF phases and the interfacial polarization between the ferritepiezoelectric interfaces, unsaturated $P-E$ hysteresis loops were obtained for all PZT-ferrite polymer films (Figs. 5(a) and 5(b)). According to that it is not possible to compare the saturation polarization for different samples, but still the comparison between the values at certain field strength could give an insight into developed ferroelectric properties of obtained flexible films. In general, low values of remanent polarization $P_{\mathrm{r}}$ were expected since ferroelectric properties are being diluted in the composite materials due to the existence of non-ferroelectric ferrite phase. $P_{\mathrm{r}}$ also decreases with increasing of ferrite constituent in the composite, which is probably connected with dielectric loss increase and heterogeneous conduction between ferroelectric and ferromagnetic interfaces [23]. Usually, PVDF must be subjected to very high electric field intensities (around 1200-1500 kV/cm) for observing saturation of polarization [24]. Having in mind that $\alpha$-PVDF, among other PVDF phases is inactive nonpolar, it does not exhibit ferroelectric behavior. Thus the ferroelectric measurements of $\alpha-\mathrm{PVDF}$ (Fig. 5(c))
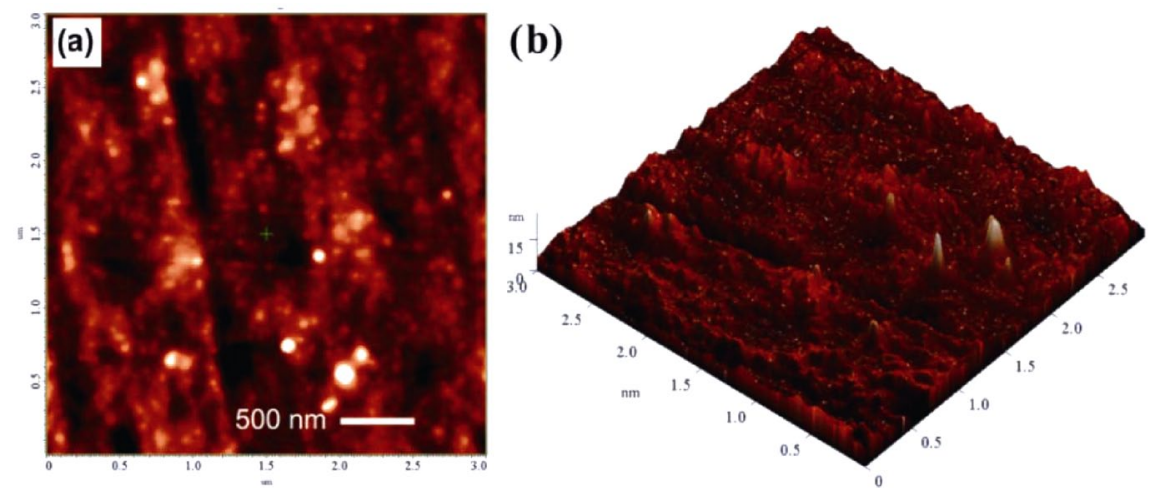

Fig. 4 (a) Two-dimensional (2D) and (b) three-dimensional (3D) AFM images of surface topography of PVDF-PZT-ferrite composite film. 

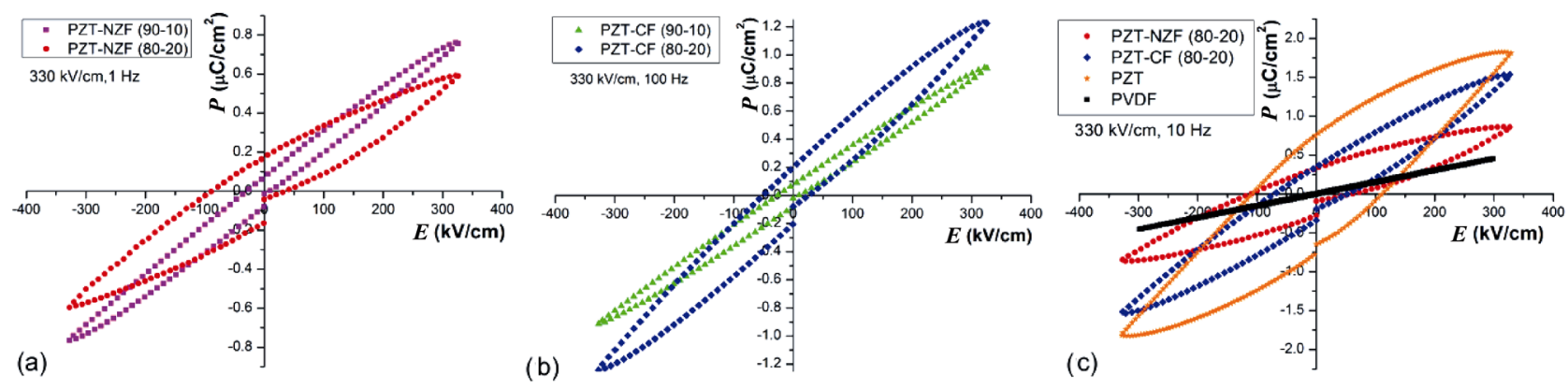

Fig. 5 Polarization hysteresis loops of (a) PVDF-PZT-NZF, (b) PVDF-PZT-CF, and (c) PVDF, PVDF-PZT and PVDF-PZT-NZF/CF (80-20) films.

confirmed dielectric behavior with no hysteresis loop up to $300 \mathrm{kV} / \mathrm{cm}$. Typical nonlinear hysteresis loop was obtained for PZT-PVDF film showing remnant polarization $\left(P_{\mathrm{r}} \approx 0.8 \mu \mathrm{C} / \mathrm{cm}^{2}\right)$ and maximal coercive field $\left(E_{\mathrm{c}} \approx 110 \mathrm{kV} / \mathrm{cm}\right)$. All hysteresis loops clearly display an enhancement in remanent polarization and coercive field values as compared to pure PVDF films.

The hysteresis measurements at the maximum electric field of $300 \mathrm{kV} / \mathrm{cm}$ revealed similar values of $P_{\mathrm{r}}\left(0.31 \mu \mathrm{C} / \mathrm{cm}^{2}\right)$ for PZT-CF and PZT-NZF composite films, but still higher maximum polarization is reached in CF-containing sample $\left(P_{\mathrm{s}}=1.01 \mu \mathrm{C} / \mathrm{cm}^{2}\right.$, see Fig. $5(\mathrm{c}))$, than in PZT-NZF films $\left(P_{\mathrm{s}}=0.61 \mu \mathrm{C} / \mathrm{cm}^{2}\right)$. This behavior can be ascribed to the existence of more pronounced conduction mechanisms in CF-based composites that are intrinsic of magnetic compounds, which overlap with the ferroelectric response of the ferroelectric phase. Conduction in composite materials is normally attributed to oxygen vacancies created due to the presence of $\mathrm{Fe}^{3+}$ and $\mathrm{Fe}^{2+}$ ions (polaron mechanism) as well as $\mathrm{Ti}^{4+}$ and $\mathrm{Ti}^{3+}$ and the charge accumulation at ferroelectric-magnetic interfaces (so-called MaxwellWagner relaxation mechanism) which is characteristic to heterogeneous systems (containing regions with different conductivities). This effect gives rise to an increase in current instead of inducing electric polarization with the applied electric field, resulting in a high-loss and unsaturated hysteresis loop. It is interesting to note that the films with higher contribution of PZT have a lower remanent polarization in both types of ferrite composites. However, these films showed lower electrical conductivity which resulted in lower leakage current (see Fig. 6) manifested through the narrower shape of the hysteresis loop.

In parallel with polarization measurements, leakage current density $(J)$ was measured as a function of static electric-field $(E)$ in order to study the conductivity mechanism in the material (Fig. 6(a)). As in the case of ferroelectric measurements, the leakage current density has not reached the saturation. In a low field region the leakage current is low; however, it increases rapidly with increasing the applied electric field. Leakage current densities of NZF based composites are lower than the leakage current density of CF based composites. Having in mind that the leakage current is related to the electric conductivity, it implies higher electrical conductivity of PZT-CF composite films in comparison with PZT-NZF. On the other hand, the leakage current
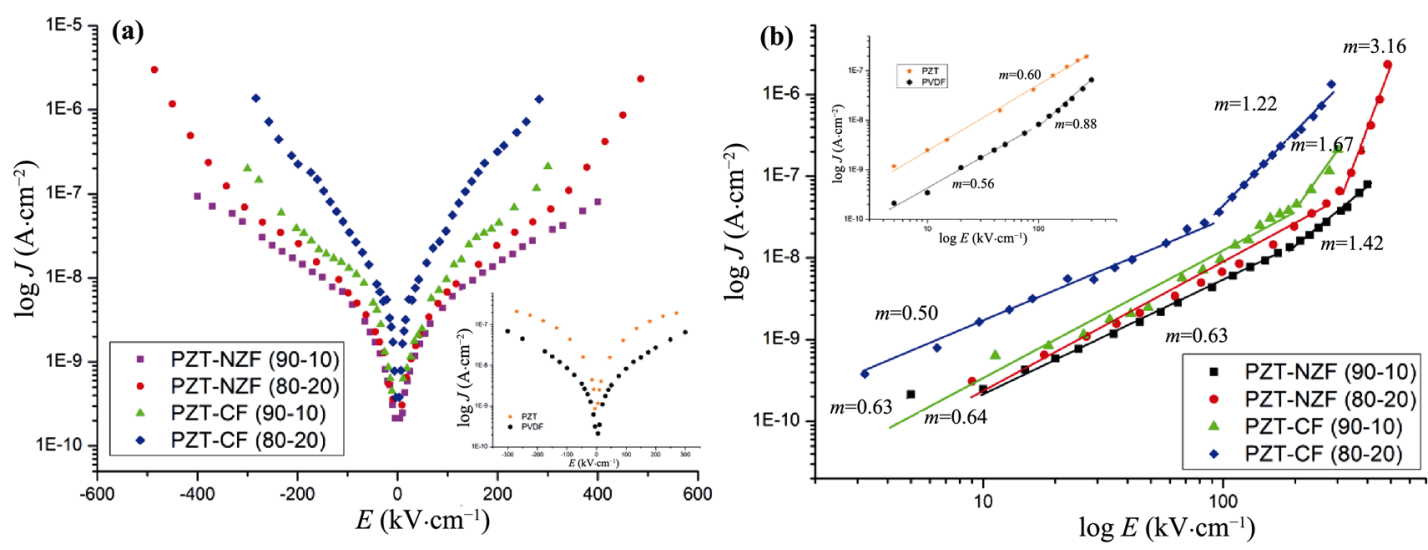

Fig. 6 Leakage current measurements presented in the form of (a) $\log J-E$ and (b) $\log J-\log E$. 
of PZT-PVDF is higher than in pure PVDF (see inserted figure) due to the presence of oxygen vacancies in the PZT filler. Having in mind that the leakage current of PZT-PVDF is similar with leakage current of PZTPVDF-ferrites, the influence of ferrite phase is weak because the ferrite phase in small quantity is only discontinuously imbedded in the PZT ferroelectric matrix.

The conduction mechanism in all samples has been analyzed by plotting $\log J$ versus $\log E$ (Fig. 6(b)), in which nearly straight lines with two different regions of slope are observed. These curves can be well fitted with power law: $J \propto E^{m}$, where " $m$ " is the slope of the curve in the logarithmic plot which determines the nature of conduction [25]. In the low field region, " $m$ " is less than 1, which probably indicates the electrodelimited conduction mechanisms (Schootky emission mechanism) that rely on the electrical property at the electrode-film interface [26,27]. This type of mechanism is dominant in both PZT-PVDF and PVDF films in whole field region. For higher field region, the slope " $m$ " is found to be between 1 and 2 for all PZT-PVDF-ferrite samples except PZT-NZF (80-20), confirming bulk-limited conduction mechanism which includes the co-existence of Ohmic as well as the Space Charge Limited Conduction (SCLC) mechanism. For PZT-NZF (80-20) sample the slope of the curve is much higher ( $m$ is around 3 ) which indicates that the Poole-Frenkel emission mechanism dominates.

Magnetic properties of composite flexible films at room temperature are shown in Fig. 7. The magnetization hysteresis $(M-H)$ loops are well saturated and indicated the presence of ordered magnetic structure due to the presence of NZF and CF phases. The estimated values of saturation magnetization $\left(M_{\mathrm{s}}\right)$, remnant magnetization $\left(M_{\mathrm{r}}\right)$, and coercive field $\left(H_{\mathrm{c}}\right)$ of the composites are listed in Table 1. The higher values of $M_{\mathrm{r}}$ are observed with increasing the concentration of ferrites in both types of films. Also, similarly as in the case of the ceramics [21], higher values of coercive field $\left(H_{\mathrm{c}} \approx 1500\right.$ Oe) are observed in the composites containing the cobalt ferrite which belongs to the group of semi-hard ferrites and it is characterized by high coercivity as reflected on the magnetic properties of the composites. On the other hand, composites containing NZF which is a soft ferrite with low coercivity possessed lower values of $H_{\mathrm{c}}$ and around 250 Oe. Further, the higher $M_{\mathrm{r}}$ is observed in semi-hard PZT-CF composites in comparison with PZT-NZF (Fig. 7(c)). As it was expected, the existence of ferroelectric phase together with ferrite phase results in decrease of magnetic parameters in comparison with pure ferrites. Generally, the magnetic properties are affected by the degree of the magnetic phase dispersed in composites.

The dielectric properties of the composites are influenced not only by the relative permittivity of the polymer and the filler, but also by other factors such as the morphology of the filler, dispersion, volume fraction of the filler, and the interactions between the two phases [28]. The temperature dependence of the dielectric constant of all specimens at different frequencies is shown in Fig. 8. For each composite the dielectric constant is almost independent of frequency in the low temperature region (up to $200 \mathrm{~K}$ ) while above this temperature dispersed regions appear. The main dispersion region is located between 200 and 350 $\mathrm{K}$. Its main feature is the shift of the maximum of dielectric loss toward higher temperatures with the increase of the measurement frequency. Such its behavior generally means that the dipolar system has a broad distribution of relaxation time [29]. In our composites this dispersion can be attributed to amorphous relaxation of PVDF, particularly to the freezing of dipolar motions since it is seen in pure PVDF as well as in PZT-PVDF and PZT-PVDF-

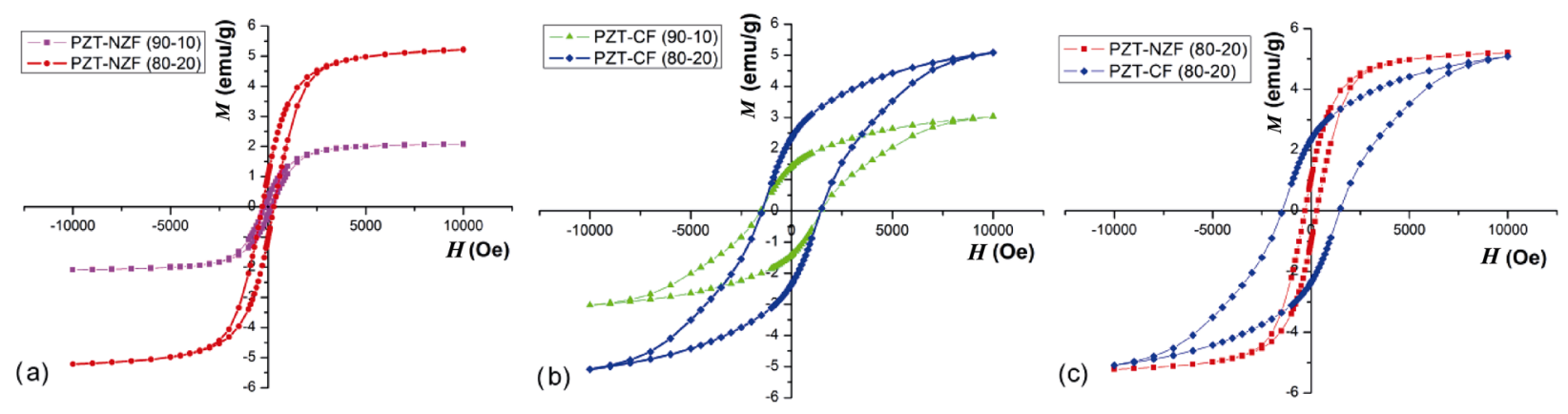

Fig. 7 Room temperature magnetic hysteresis $M-H$ loops of all composite ceramic films. 
Table 1 Saturation magnetization $\left(M_{\mathrm{s}}\right)$, remanent magnetization $\left(M_{\mathrm{r}}\right)$, and coercive field $\left(H_{\mathrm{c}}\right)$ of all composites

\begin{tabular}{ccccc}
\hline Sample & $M_{\mathrm{s}}(\mathrm{emu} / \mathrm{g})$ & $M_{\mathrm{r}}(\mathrm{emu} / \mathrm{g})$ & $H_{\mathrm{c}}(\mathrm{Oe})$ & $M_{\mathrm{r}} / M_{\mathrm{s}}$ \\
\hline PZT-CF (90-10) & 2.45 & 1.39 & 1454.0 & 0.57 \\
PZT-CF (80-20) & 4.48 & 2.33 & 1454.0 & 0.52 \\
PZT-NZF (90-10) & 1.97 & 0.31 & 187.9 & 0.16 \\
PZT-NZF (80-20) & 4.92 & 1.04 & 307.1 & 0.21 \\
\hline
\end{tabular}
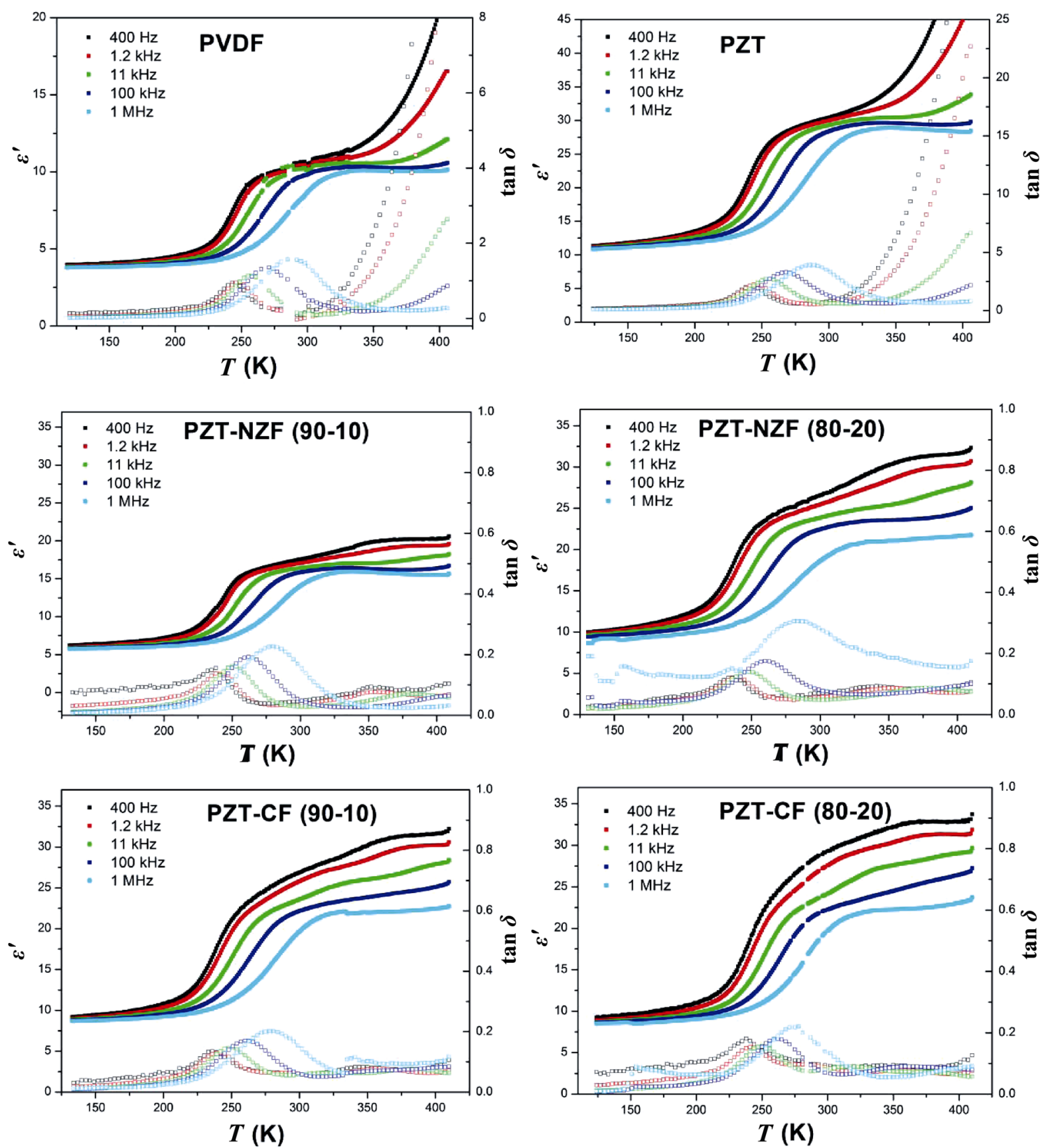

Fig. 8 Temperature dependence of the dielectric constant and $\tan \delta$ of all specimens at different frequencies ( $\varepsilon^{\prime}$ is denoted with full dots, and $\tan \delta$ is denoted with empty dots).

ferrite composites that is in agreement with results observed earlier in literature [30-32]. The second dispersion region which appears above the room temperature is partially overlapped with the PVDF 
dispersion and gets stronger above $350 \mathrm{~K}$. There is no clear definition about its origin and can be associated with the wide-angle oscillation of dipolar groups of PVDF [31] or with Maxwell-Wagner relaxation induced by chemical inhomogeneity thus forming space charge-rich regions between PZT and CF/NZF and PVDF matrix. Most probably in all investigated composites, the superposition of both phenomena occurs.

Figure 9 shows the frequency dependence of $\varepsilon$ ' and $\tan \delta$ of all composites at room temperature. For each composite, the dielectric permittivity has shown several partially overlapped dispersion regions indicated by the change in the slope of curves and subsequent jumps in dielectric losses. These low-frequency relaxations of $\varepsilon$ ' appearing at low frequencies below $400 \mathrm{kHz}$ in all samples can be referred to defects creating interface polarization owing to the charge accumulation at the boundary between different phases caused by different Maxwell-Wagner polarization mechanism and may be predominating in the total conduction of this family of materials. The relaxation dispersion starting to emerge above $400 \mathrm{kHz}$ is obviously related to the glass transition relaxation of the PVDF matrix [31,32,35].

Figure 9 shows that pure PVDF film has dielectric constant around 10 in whole frequency range at room temperature. Dielectric constant of PZT-PVDF showed $\sim 30$ which was 3 times higher than pure PVDF. Similar improvement in dielectric constant of polymers was obtained in other BT-TPU and PZT-PVDF polymer systems $[9,35,36]$. All other PZT-NZF/CF composites showed enhancement of dielectric constant in comparison to pure PVDF, but still lower than PZT-PVDF. Possible reason could be the depolarization

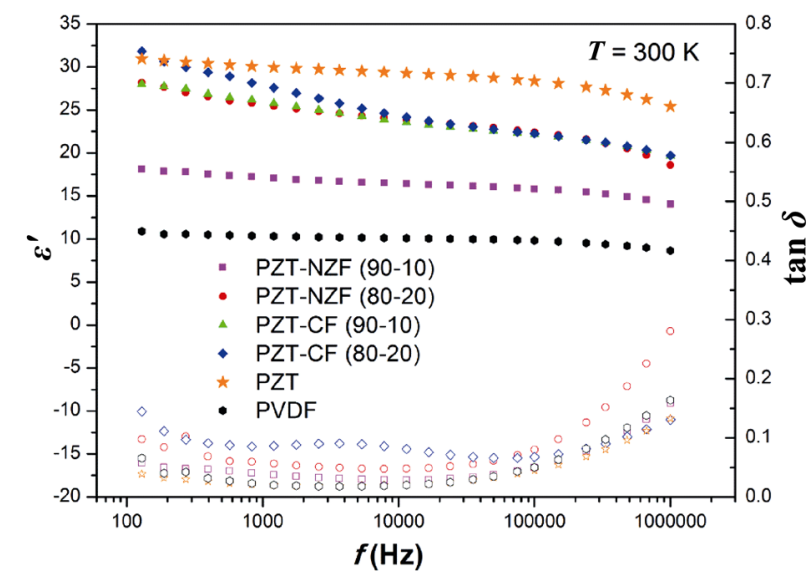

Fig. 9 Frequency dependence of $\varepsilon^{\prime}$ and $\tan \delta$ of all specimens at room temperature ( $\varepsilon^{\prime}$ is denoted with full dots, and $\tan \delta$ is denoted empty dots). of the NZF/CF filler while incorporating in the polymer matrix, since polymer matrix obscures the polarizability of the ceramic filler.

Since this relaxation extends well into microwave region, it was impossible to perform any detailed analysis of it like it was done in Ref. [32]. Instead, an analysis of the dielectric losses, whose maximum at particular temperature reflects the relaxation time, was done. Figure 10 shows the inverse temperature dependence of the relaxation time $\tau$ calculated according to relation $\tau=1 / f_{\max }$ where $f_{\max }$ is the frequency at which dielectric losses have a maximum. It is apparent that the relaxation time behaves nonexponentially in the $250-300 \mathrm{~K}$ temperature window, i.e., where the PVDF-related relaxation dominates the dielectric spectra. Thus it was fitted with Vogel-Fulcher empirical relationship $\tau=\tau_{0} \exp \left[E_{\mathrm{a}} /\left(T-T_{\mathrm{F}}\right)\right]$ where $\tau_{0}$ is the relaxation frequency at (very) high temperatures, $E_{\mathrm{a}}$ is the activation energy of the process, and $T_{\mathrm{F}}$ represents the temperature at which dipolar motion undergoes the freezing, i.e., its dynamics becomes infinitely slow and the system shows the glassy freezing at this temperature [29]. The parameters of the fits are presented in Table 2. The same order of magnitude of relaxation frequency was observed for pure PVDF and PZT-PVDF films as well as similar values of freezing temperature and $E_{\mathrm{a}}$. Further, it is obvious that all parameters for different PVDF-PZT-ferrite samples are close to each other and despite the smaller value of $\varepsilon$ ' of PZT-NZF (90-10) composite $(\sim 16$ at $100 \mathrm{kHz})$ compared to the other samples ( 22 at $100 \mathrm{kHz})$, no significant changes exist between them. One can state performing more careful examination of Vogel-Fulcher fitting parameters that the addition of magnetic phase increases the freezing temperature of composites and subsequently decreases their activation energy.

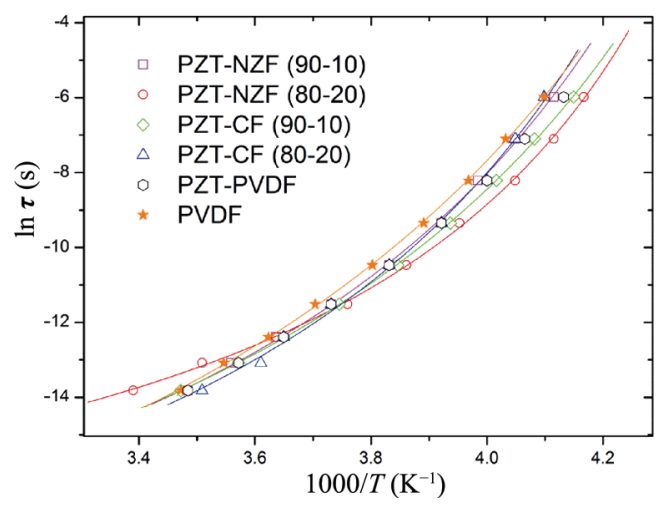

Fig. 10 Inverse temperature dependence of the relaxation time for all samples. 
Table 2 Voleg-Fulcher fit parameters of all composites

\begin{tabular}{lccc}
\hline \multicolumn{1}{c}{ Sample } & $\tau_{0}(\mathrm{~s})$ & $E_{\mathrm{a}}(\mathrm{eV})$ & $T_{\mathrm{F}}(\mathrm{K})$ \\
\hline PZT-NZF (90-10) & $2.7 \times 10^{-10}$ & 0.06 & 196 \\
PZT-NZF (80-20) & $7.5 \times 10^{-9}$ & 0.04 & 205 \\
PZT-CF (90-10) & $2.9 \times 10^{-10}$ & 0.07 & 192 \\
PZT-CF (80-20) & $3.2 \times 10^{-10}$ & 0.06 & 201 \\
PZT-PVDF & $8.3 \times 10^{-11}$ & 0.08 & 188 \\
PVDF & $4.7 \times 10^{-11}$ & 0.09 & 187 \\
\hline
\end{tabular}

\section{Conclusions}

In summary, the three-phase PZT-NZF/CF composite thick flexible films, as well as pure PVDF and PZTPVDF films were successfully fabricated by hot press method. SEM results showed that the ceramic particles of ferroelectric and ferrite phases were dispersed homogeneously in the PVDF matrix while AFM confirmed that the size of the particles is around $30 \mathrm{~nm}$. $P-E$ hysteresis loops of PVDF-PZT-ferrite show unsaturated lossy loop which is further ascribed to the relatively high conductivity of NZF/CF phases. Leakage current density measurements confirmed that NZF-containing composites are less conductive than CF-containing ones. Magnetic measurements confirmed that the higher $M_{\mathrm{r}}$ is observed in semi-hard PZT-CF composites in comparison with soft PZT-NZF films. The existence of ferroelectric PZT phase, and its increase, result in decrease of all magnetic parameters. Value of dielectric constant of pure PVDF film $(\sim 10)$ is found to be enlarged by addition of PZT and $\mathrm{PZT}-\mathrm{NZF} / \mathrm{CF}$ fillers and the values are around 30 and 22 , respectively.

\section{Acknowledgements}

The results presented in this paper are realized with the financial support of Ministry of Education, Science and Technological Development of the Republic of Serbia trough the project III 45021 .

\section{References}

[1] Moazzami R, Hu C, Shepherd WH. Electrical characteristics of ferroelectric PZT thin films for DRAM application. IEEE T Electron Dev 1992, 39: 2044-2049.

[2] Ahn Y, Seo J, Lim D, et al. Ferroelectric domain structures and polarization switching characteristics of polycrystalline $\mathrm{BiFeO}_{3}$ thin films on glass substrates. Curr Appl Phys 2015,

\section{5: 584-587.}

[3] Pramoda KP, Huang A, Shannigrahi SR. On some properties of PZT-NZF composite films manufactured by hybrid synthesis route. Ceram Int 2011, 37: 431-435.

[4] Gupta R, Rana L, Tomar M, et al. Characterization of lead zirconium titanate thin films based multifunctional energy harvesters. Thin Solid Films 2018, 652: 39-42.

[5] Stojanovic BD, Dzunuzovic AS, Ilic NI, et al. 27-Complex composites: Polymer matrix-ferroics or multiferroics. In: Magnetic, Ferroelectric, and Multiferroic Metal Oxides. Stojanovic BD, Ed. Elsevier, 2018: 559-569.

[6] Hwang GT, Byun M, Jeong CK, et al. Flexible piezoelectric thin-film energy harvesters and nanosensors for biomedical applications. Adv Healthcare Mater 2014, 4: 646-658.

[7] Almusallam A, Luo ZH, Komolafe A, et al. Flexible piezoelectric nano-composite films for kinetic energy harvesting from textiles. Nano Energy 2017, 33: 146-156.

[8] Behera C, Choudhary RNP, Das PR. Development of multiferroic polymer nanocomposite from PVDF and $\left(\mathrm{Bi}_{0.5} \mathrm{Ba}_{0.25} \mathrm{Sr}_{0.25}\right)\left(\mathrm{Fe}_{0.5} \mathrm{Ti}_{0.5}\right) \mathrm{O}_{3}$. J Mater Sci: Mater Electron 2017, 28: 2586-2597.

[9] Khan MN, Jelani N, Li C, et al. Flexible and low cost lead free composites with high dielectric constant. Ceram Int 2017, 43: 3923-3926.

[10] Pascariu V, Padurariu L, Avadanei O, et al. Dielectric properties of PZT-epoxy composite thick films. $J$ Alloys Compd 2013, 574: 591-599.

[11] Pascariu V, Avadanei O, Gasner P, et al. Preparation and characterization of $\mathrm{PbTiO}_{3}$-epoxy resin compositionally graded thick films. Phase Transitions 2013, 86: 715-725.

[12] Badapanda T, Senthil V, Anwar S, et al. Structural and dielectric properties of polyvinyl alcohol/barium zirconium titanate polymer-ceramic composite. Curr Appl Phys 2013, 13: 1490-1495.

[13] Namitha LK, Sebastian MT. High permittivity ceramics loaded silicone elastomer composites for flexible electronics applications. Ceram Int 2017, 43: 2994-3003.

[14] Wang ST, Sun J, Tong L, et al. Superior dielectric properties in $\mathrm{Na}_{0.35 \%} \mathrm{Ba}_{99.65 \%} \mathrm{Ti}_{99.65 \%} \mathrm{Nb}_{0.35 \%} \mathrm{O}_{3} / \mathrm{PVDF}$ composites. Mater Lett 2018, 211: 114-117.

[15] Adhlakha N, Yadav KL, Truccato M, et al. Reduced leakage current and improved multiferroic properties of $0.5((1-x)$ BLPFO- $x$ PZT $)-0.5$ PVDF composite films. Ceram Int 2016, 42: 18238-18246.

[16] Luo BC, Wang XH, Wang YP, et al. Fabrication, characterization, properties and theoretical analysis of ceramic/PVDF composite flexible films with high dielectric constant and low dielectric loss. J Mater Chem A 2014, 2: 510-519.

[17] Ruan L, Yao X, Chang Y, et al. Properties and applications of the $\beta$ phase poly(vinylidene fluoride). Polymers 2018, 10: 228.

[18] García-Zaldívar O, Escamilla-Díaz T, Ramírez-Cardona M, et al. Ferroelectric-paraelectric transition in a membrane with quenched-induced $\delta$-phase of PVDF. Sci Rep 2017, 7: 
$5566-5573$.

[19] Sencadas V, Gregorio Jr. R, Lanceros-Méndez S. $\alpha$ to $\beta$ phase transformation and microestructural changes of PVDF films induced by uniaxial stretch. $J$ Macromol Sci Part B 2009, 48: 514-525.

[20] Li L, Zhang MQ, Rong MZ, et al. Studies on the transformation process of PVDF from $\alpha$ to $\beta$ phase by stretching. RSC Adv 2014, 4: 3938-3943.

[21] Popielarz R, Chiang CK. Polymer composites with the dielectric constant comparable to that of barium titanate ceramics. Mat Sci Eng B 2007, 139: 48-54.

[22] Bobić JB, Ivanov M, Ilić NI, et al. PZT-nickel ferrite and PZT-cobalt ferrite comparative study: Structural, dielectric, ferroelectric and magnetic properties of composite ceramics. Ceram Int 2018, 44: 6551-6557.

[23] Adhlakha N, Yadav KL. Study of structural, dielectric and magnetic behaviour of $\mathrm{Ni}_{0.75} \mathrm{Zn}_{0.25} \mathrm{Fe}_{2} \mathrm{O}_{4}-\mathrm{Ba}\left(\mathrm{Ti}_{0.85} \mathrm{Zr}_{0.15}\right) \mathrm{O}_{3}$ composites. Smart Mater Struct 2012, 21: 115021.

[24] Suresh G, Jatav S, Ramachandra Rao MS, et al. Enhancement of dielectric and ferroelectric properties in cobalt ferrite doped poly(vinylidene fluoride) multiferroic composites. Mater Res Express 2017, 4: 075301.

[25] Godara S, Kumar B. Effect of Ba-Nb co-doping on the structural, dielectric, magnetic and ferroelectric properties of $\mathrm{BiFeO}_{3}$ nanoparticles. Ceram Int 2015, 41: 6912-6919.

[26] Cai W, Gao RL, Fu CL, et al. Microstructure, enhanced electric and magnetic properties of $\mathrm{Bi}_{0.9} \mathrm{La}_{0.1} \mathrm{FeO}_{3}$ ceramics prepared by microwave sintering. J Alloys Compd 2019, 774: 61-68.

[27] Lim EW, Ismail R. Conduction mechanism of valence change resistive switching memory: A survey. Electronics 2015, 4: 586-613.

[28] Jain A, Prashanth KJ, Sharma AK, et al. Dielectric and piezoelectric properties of PVDF/PZT composites: A review. Polym Eng Sci 2015, 55: 1589-1616.

[29] Banys J, Grigalaitis R, Mikonis A, et al. Distribution of relaxation times of relaxors: Comparison with dipolar glasses. Phys Status Solidi C 2009, 6: 2725-2730.

[30] Suresh G, Jatav S, Geethu PM, et al. Poly(vinylidene
fluoride)-Formvar blends: Dielectric, miscibility and mechanical studies. J Phys D: Appl Phys 2018, 51: 065604.

[31] Hilczer B, Kułek J, Markiewicz E, et al. Dielectric relaxation in ferroelectric PZT-PVDF nanocomposites. $J$ Non-Cryst Solids 2002, 305: 167-173.

[32] Svirskas S, Simenas M, Banys J, et al. Dielectric relaxation and ferromagnetic resonance in magnetoelectric (polyvinylidene-fluoride)/ferrite composites. J Polym Res 2015, 22: 141.

[33] Zhou WY, Dong LN, Sui XZ, et al. High dielectric permittivity and low loss in PVDF filled by core-shell Zn@ZnO particles. J Polym Res 2016, 23: 45.

[34] Fu J, Hou YD, Zheng MP, et al. Improving dielectric properties of PVDF composites by employing surface modified strong polarized $\mathrm{BaTiO}_{3}$ particles derived by molten salt method. ACS Appl Mater Interfaces 2015, 7: 24480-24491.

[35] Singh P, Borkar H, Singh BP, et al. Ferroelectric polymer-ceramic composite thick films for energy storage applications. AIP Adv 2014, 4: 087117.

[36] Chen G, Lin X, Li J, et al. Enhanced dielectric properties and discharged energy density of composite films using submicron PZT particles. Ceram Int 2018, 44: 15331-15337.

Open Access This article is licensed under a Creative Commons Attribution 4.0 International License, which permits use, sharing, adaptation, distribution and reproduction in any medium or format, as long as you give appropriate credit to the original author(s) and the source, provide a link to the Creative Commons licence, and indicate if changes were made.

The images or other third party material in this article are included in the article's Creative Commons licence, unless indicated otherwise in a credit line to the material. If material is not included in the article's Creative Commons licence and your intended use is not permitted by statutory regulation or exceeds the permitted use, you will need to obtain permission directly from the copyright holder.

To view a copy of this licence, visit http://creativecommons.org/licenses/by/4.0/. 